\title{
Educadores e a implementação de diretrizes contra desigualdades: o caso do ProJovem Urbano'
}

Maria Inês Caetano Ferreira"l

\section{Resumo}

0 artigo apresenta e discute resultados de uma pesquisa com educadores do ProJovem Urbano na Região Metropolitana de São Paulo. 0 objetivo foi investigar as experiências dos educadores com a implementação das diretrizes desse programa e a possibilidade de construção de relações entre professor e aluno marcadas pelo respeito à diferença e compromissadas com a inclusão. A orientação teórica apoia-se nos estudos que abordam a escola como lugar de reprodução das desigualdades sociais, nos autores que estudam os modos como se dão as relações entre a lógica escolar e as formas de socialização das famílias populares, e também nas investigações sobre escola e diversidade cultural. As linhas teóricas destacam o processo que converte diferenças em desigualdades. Foram realizadas entrevistas em profundidade com educadores do ProJovem a fim de compreender se os objetivos e as diretrizes do programa aproximam educadores e educandos e promovem a produção conjunta do conhecimento, contribuindo para a construção de relações mais justas e respeitosas entre professores e alunos. Os resultados comprovam essa possibilidade, elucidando o papel-chave do educador na implementação do programa. Além disso, também são desvendados problemas como a falta de apoio aos educadores e a precariedade da relação de trabalho, os quais podem prejudicar os resultados do ProJovem.

\section{Palavras-chave}

ProJovem Urbano - Políticas de educação - Políticas de juventude.

I- Agradeço a todos os educadores desse ProJovem a convivência que me ensinou a ser uma educadora. Agradeço também aos avaliadores desta revista, cuja leitura minuciosa me permitiu compreender melhor meu próprio trabalho.

II- Universidade Federal do Recôncavo da

Bahia, Salvador, BA, Brasil.

Contato: inesferreira15@yahoo.com.br 


\section{Educators and the implementation of guidelines against inequality: the case of the ProJovem Urbano Program'}

Maria Inês Caetano Ferreira"l

\begin{abstract}
The article presents and discusses results of a research with educators from the ProJovem Urbano (Urban ProYoungster) Program of the Metropolitan Region of São Paulo. The objective was investigating the experiences of the educators with the implementation of the program guidelines, and the possibility of building teacher-pupil relations characterized by the respect for difference and commitment to inclusion. The theoretical orientation is based on studies that see schools as a place for the reproduction of social inequalities, on authors that study how the relations between the school logics and the forms of socialization of popular families take place, and also on investigations about school and cultural diversity. The theoretical directions emphasize the process that converts differences in inequalities. In-depth interviews were carried out with educators from the ProJovem Program in order to understand whether the objectives and guidelines of the program bring educators and educated closer, helping to promote the joint production of knowledge, and contributing to the construction of more fair and respectful relations between teachers and pupils. The results confirm this possibility, clarifying the key role of the educator in the implementation of the program. Besides, the study also revealed problems such as the lack of support to educators and the precariousness of the work relations, which can jeopardize the results of the program.
\end{abstract}

\section{Keywords}

ProJovem Urbano - Education policies - Youth policies.
I- I wish to thank to all ProJovem educators for the experience that taught me how to be an educator. I also wish to thank the reviews of this journal whose careful reading allowed me to better understand my own work.

II- Universidade Federal do Recôncavo da

Bahia, Salvador, Bahia, Brazil.

Contact: inesferreira15@yahoo.com.br 


\section{A desigualdade nas relações entre o sistema escolar e as famílias populares}

As relações entre as famílias populares e a escola têm sido marcadas por diferenças e conflitos investigados por extensa literatura. Nesse confronto, os valores e conhecimentos produzidos e transmitidos na escola geralmente desfrutam de mais legitimidade do que aqueles oriundos das famílias populares, estimulando a conversão das diferenças em desigualdade.

Bourdieu refletiu sobre a escola como um ambiente de reprodução da desigualdade social. Mendes e Seixas (2003) lembram que, em Os herdeiros, Bourdieu e Passeron questionam a neutralidade e a tecnicidade da avaliação ao justificar o fracasso dos alunos em virtude de uma menor capacidade de aquisição da cultura escolar. Os autores vinculam o sistema de ensino à dominação por meio de seleção social. Esse sistema legitimaria práticas e representações das classes dominantes, em oposição às não dominantes.

Para Thin (2010), em sua reflexão sobre a escola como ambiente de reprodução da desigualdade social, as classes populares aparecem como submissas, sem autonomia simbólica. Ele argumenta que a noção de capital cultural não atenta para os modos como se dão as relações entre pais e escola e como os primeiros se apropriam da escolarização de seus filhos, tema este sobre o qual o autor se debruça (THIN, 2006).

Paixão (2005) também investiga as interações entre famílias populares e escola. Segundo a autora, para a escola, os pais deveriam participar ativamente do processo de aprendizagem. Contudo, como também observa Thin (2010), não é incomum que eles discorram mais sobre questões domésticas do que sobre as pedagógicas, em virtude de não sobreporem a escola a outras esferas da vida. Em estudo com catadoras de lixo, Paixão (2005) indica que as famílias priorizam a dimensão afetiva e relacional em detrimento da cognitiva, que é estimada pelo sistema escolar. Outra diferença captada pela autora é a despreocupação dessas mães com a distorção série-idade, em contraste com a relevância atribuída pela escola.

Thin (2006) conclui que as diferenças entre a lógica escolar e as práticas socializadoras das famílias populares se explicam pelas condições de vida dessas últimas. A aprendizagem na escola se efetua em tempo e espaço específicos, separados do mundo cotidiano e da prática, apoiando-se em exercícios elaborados para essa finalidade. Em oposição, a socialização das famílias populares se assenta na prática, na vida cotidiana. A forma de linguagem na escola emprega conceitos e raciocínios abstratos, ultrapassando os limites da realidade concreta; nas famílias, ela é contextualizada, referindo-se a elementos próximos. A lógica escolar se ancora no planejamento a longo prazo, mas a forma instável de inserção ocupacional retém as famílias nas soluções cotidianas. Vale destacar que as famílias legitimam a lógica escolar, mas esta não prestigia a forma de socialização daquelas. Desse modo, mais do que diferentes, elas se tornam desiguais.

A literatura especializada em diversidade cultural chama atenção para outros elementos envolvidos na relação entre famílias e escola, tais como gênero, etnia, migração, religião etc. Candau (2001) elucida a ambivalência entre igualdade e homogeneidade que se originou ao longo da luta pela igualdade de todos os cidadãos, levando alguns a uma confusão em relação à formação de uma cultura comum a que todos deveriam ter acesso. Tal ambivalência, nessa perspectiva, teria negado e silenciado as diferenças. De certo modo, conforme explica a autora, a expansão de acesso aos direitos trouxe consigo o embaraço da incorporação dos excluídos a uma cultura comum e hegemônica, denominada política assimilacionista. Candau (2001) salienta que essa lógica orientou a universalização da educação, tendo como uma de suas consequências a associação feita por muitos professores entre diferença e problema, falta e fracasso.

A adesão a um padrão hegemônico de cultura resulta em problemas, principalmente 
no caso do Brasil, nação caracterizada pela diversidade de sua população. Para Canen (2001), essa hegemonia provoca a exclusão de grupos sociais que desenvolvem padrões diferentes, porque a distinção opera na formação de estereótipos associados ao fracasso escolar.

As observações dessas autoras chamam atenção para o fato de que os fundamentos da socialização das famílias populares englobam várias lógicas de diferentes grupos. Tais lógicas se entrecruzam e se atualizam por conteúdos relacionados a etnia, sexo, experiências religiosas, local de origem, preconceitos relativos à migração, residência em área de ocupação irregular e muitos outros.

No Brasil, o direito dos cidadãos à diferença é reconhecido e acolhido pela escola pública. Todavia, a implementação de diretrizes que buscam afırmar esse direito não é um compromisso simples. Em pesquisa realizada sobre o ensino médio, Leão, Dayrell e Reis (2011) verificam que as singularidades sociais, de gênero, de etnia e outras próprias de jovens não são consideradas no espaço escolar. Os autores constatam que a escola não contempla a vida dos jovens que acontece fora de seu espaço, seguindo descontextualizada, sem dialogar com a realidade social na qual deveria atuar. Em outro artigo, Leão (2006) chama atenção para a importância de os estudantes estabelecerem relação subjetiva com o mundo escolar, associando-o às suas demandas. Sem isso, eles podem não atribuir utilidade à escola e se desenvolverem paralelamente a ela, tal como se verifica na experiência de estudantes jovens e pobres no ensino médio da rede pública.

\section{Programa Nacional de Inclusão de Jovens - ProJovem}

O Programa Nacional de Inclusão de Jovens (ProJovem) foi implantado em 2005 com o objetivo de elevar a escolaridade dos jovens por meio da conclusão do ensino fundamental, da qualificação profissional, do estímulo à inserção produtiva e à ação comunitária, despertando solidariedade, exercício de cidadania e ação local. 0 programa sofreu mudanças em 2007, sendo subdividido. Esta pesquisa aborda o ProJovem que manteve os princípios do original, denominado Urbano. 0 público do programa é de jovens entre 18 e 29 anos com ensino fundamental incompleto, mas que saibam ler e escrever, mesmo sem nunca ter frequentado até a $4^{\text {a }}$ série. 0 estudante recebe uma bolsa no valor de $\mathrm{R} \$ 100,00$. A carga horária é de dezoito meses, com um total de duas mil horas (1.092 horas para formação básica, 390 horas para qualificação profissional, 78 horas para participação cidadã, 440 horas não presenciais). 0 programa é desenvolvido nas escolas públicas. Recentemente houve novas alterações em sua configuração, as quais não são aqui consideradas.

0 currículo do ProJovem se divide em três ciclos, sendo cada um com a duração total de seis meses e composto por duas unidades formativas (de três meses cada). Os conteúdos de língua portuguesa, matemática, ciências humanas, ciências da natureza, língua inglesa, qualificação profissional e participação cidadã são desenvolvidos de forma integrada ao longo dos ciclos (FÉRES, 2008). 0 material didático se compõe de quatro guias multidisciplinares, com textos básicos e todos os conteúdos.

A finalidade básica do programa é a formação integral dos jovens, incluindo a educação básica, a qualificação profıssional e a ação social. Suas finalidades específicas envolvem a ampliação da capacidade de produção e comunicação, bem como a inclusão digital e cultural (BRASIL, 2008).

Seus objetivos gerais buscam oferecer oportunidade de novas formas de interação, apropriação de novos conhecimentos, reelaboração de experiências e visão de mundo a fim de que os jovens possam: afirmar sua dignidade como seres humanos, cidadãos e trabalhadores; utilizar a leitura e a escrita; planejar projeto profissional; apreciar dimensão estética; assumir responsabilidade com o grupo; conviver e trabalhar em equipe; posicionar-se ativamente contra a discriminação; exercer direitos e continuar estudando ao longo da vida. 
Algumas das várias diretrizes operacionais do ProJovem são as seguintes: valorizar as experiências e os conhecimentos prévios dos jovens, tomando-os como ponto de partida da aprendizagem; reconhecer e valorizar as diferenças de gênero, etnia etc.; orientar atividades de ensino de acordo com potencialidades e ritmos específicos; adaptar conteúdos de ensino às peculiaridades locais; registrar as próprias trajetórias familiares e comunitárias etc.

Os objetivos e as diretrizes elencados esclarecem que o programa valoriza a diferença, pois o estudante é acolhido como ponto de partida do processo de aprendizagem, em oposição à representação de um aluno ideal, detentor de um suposto conhecimento considerado elementar pela escola. A proposta do ProJovem se compromete com a lógica escolar, com o desenvolvimento de habilidades cognitivas, do raciocínio abstrato, da capacidade de planejar. Porém, ela também valoriza a contextualização e as dimensões afetivas e relacionais.

Merece destaque que o público do ProJovem vive sob situação de risco e, portanto, em intensa vulnerabilidade (COSTA, 2007). 0 trabalho de Andrade, Esteves e Oliveira (2009) descreve a realidade social dos estudantes da primeira versão do programa. Segundo os autores, $64,7 \%$ dos estudantes recebiam até meio salário mínimo e 26,9\% recebiam entre meio e um salário mínimo. Do total dos estudantes, 34,9\% alegaram ter dificuldade para conseguir emprego por falta de escolaridade. Em relação à trajetória escolar, 25,2\% dos alunos haviam interrompido os estudos por duas vezes, $24,6 \%$ interromperam uma vez e 19,6\%, por três vezes. A pesquisa de Santos (2011) com estudantes do ProJovem em Aracaju indica os motivos para o abandono escolar: 29\% saíram por causa de casamento ou gravidez; 24\% por causa de trabalho; $24 \%$ porque não queriam estudar; e 15\% porque não gostaram da escola.

\section{O ProJovem Urbano na RMSP}

Este artigo apresenta e discute os resultados de pesquisa realizada com educadores do ProJovem Urbano em município da Região Metropolitana de São Paulo com elevada densidade populacional e com economia dinâmica, destacando-se nas atividades de serviço e comércio. Vale ressaltar que o perfil dos estudantes do ProJovem corresponde a pequeno grupo nesse município, o que dificultou o preenchimento das vagas do programa.

0 município e os educadores entrevistados não são aqui identificados porque o objetivo é reconhecer e analisar a configuração da implementação de uma política de educação para a juventude. É certo que as características do município, assim como as singularidades da gestão municipal, exercem efeito nos resultados da pesquisa. Porém, os temas abordados são gerais e comuns às administrações municipais do país. Mais do que apontar a responsabilidade específica de determinada gestão pelos resultados alcançados, a proposta é conhecer e compreender o conjunto de variáveis relacionadas ao sucesso e aos obstáculos que se impõem à construção de um modelo escolar inclusivo. A identificação do município, da gestão e dos profissionais não traria contribuições aos resultados, já que estes poderiam ser idênticos em outros municípios ou gestões.

0 objetivo principal da pesquisa foi estudar a possibilidade de as diretrizes do ProJovem colaborarem (ou não) para a construção de relações entre educadores e educandos caracterizadas pelo respeito à diferença, pelo compromisso com a inclusão e pela superação do conflito entre a lógica escolar e a lógica das famílias populares. Thin (2006) e Paixão (2005) apresentam os dilemas da relação entre a escola e as famílias populares, atentando principalmente para essas últimas. 0 presente estudo investiga os educadores e o modo como eles vivenciam o conflito e a desigualdade e como atuam (ou não) para superá-los.

Vale destacar que a pesquisa não se dedicou a avaliar o êxito do programa em relação ao aproveitamento dos estudantes e à sua capacidade de aprendizagem. Os índices de aprovação e reprovação não foram considerados, pois 
relações baseadas no respeito às diferenças, por si só, não são suficientes para promover êxito no aproveitamento. Este concatena inúmeras variáveis. Destaca-se, ainda, que o desempenho nacional da avaliação externa do segundo ciclo não sugere nenhum triunfo. 0 aproveitamento em 2010 foi o seguinte: língua portuguesa, 49,9\%; matemática, 39,9\%; ciências humanas, 47\%; ciências naturais, 37,3\% (BRASIL, 2009)

\section{Metodologia}

Os primeiros passos desta pesquisa se deram entre 2008 e 2010, durante atividades de formação continuada dos educadores. Por alguns meses, a atuação limitou-se ao acompanhamento da dupla responsável pela formação, no início de cada nova unidade formativa. Depois, houve a possibilidade de realizar encontros nas escolas. Sem autonomia para definir uma alternativa para a formação continuada, os encontros foram aproveitados para a discussão das experiências cotidianas dos educadores - permitindo-lhes expor os problemas das salas de aula -, articulando-as com a teoria. Em tais encontros era possível participar do jantar na escola, dos eventos organizados por educadores e educandos, do enfrentamento de problemas com a falta de espaço para o trabalho em equipe etc. Portanto, o início da pesquisa se deu por meio de observação participante, embora nessa época ainda não houvesse o amadurecimento de uma proposta de estudo. Durante esse tempo foi possível acompanhar as discussões dos educadores sobre as dificuldades enfrentadas em sua relação com os estudantes, com a coordenação, com as regras do programa e com as deficiências da formação continuada, e sobre o entusiasmo com a evolução de alguns alunos.

Em 2012 efetuou-se o estudo da relação dos educadores do ProJovem com os educandos. Foram realizadas entrevistas com seis educadores de todas as áreas, ou seja, educação básica, qualificação profissional e ação social. 0 grupo dos entrevistados se compôs de uma professora de língua portuguesa, uma de ciências naturais, uma de ciências humanas, uma professora e um professor de qualificação profissional e uma de ação social. A divisão das áreas considerou a carga horária do programa, com predomínio da educação básica, seguida de qualificação e, finalmente, de ação social. Além desse recorte, não houve muito controle sobre o perfil dos entrevistados. Isso porque a técnica adotada foi entrar em contato com os educadores concomitantemente e marcar as entrevistas com os primeiros que aceitassem o convite. Essa técnica impediu a seleção de educadores que apresentassem concepções próximas às da pesquisadora acerca da educação de jovens de famílias populares. Ao contrário, o próprio educador impôs seu perfil às reflexões da pesquisa. Todos os entrevistados atuaram no programa, pelo menos, entre os anos de 2008 e 2010, distribuídos nos quatro núcleos do município: dois na zona norte e dois na zona sul. Dentre os entrevistados, quatro eram da zona norte e dois da zona sul.

Ao longo da observação participante, constatou-se que os educadores estavam envolvidos com as diretrizes do programa, apesar dos problemas que enfrentavam em sua implementação. Isso ficou patente nas reuniões, nos debates e nos encontros com os próprios educandos, e possibilitou uma seleção mais livre, porque já se sabia que dificilmente algum deles iria desenvolver discurso contrário à relevância da educação inclusiva. De fato, alguns eram mais críticos e engajados, mas nenhum deles se opunha a tal educação. As reuniões com os núcleos da zona norte eram movimentadas e críticas, com educadores que nunca tinham atuado na área da educação. Essa mistura proporcionava acalorados debates sobre concepções de ensino, metodologias etc. As reuniões com os núcleos da zona sul eram menos agitadas. Muitos dos educadores eram da rede pública e reclamavam das teorias que ignoravam o cotidiano da sala de aula, exigindo trabalho fino sobre como as reflexões teóricas podiam contribuir com a prática.

Vale destacar que embora as informações adquiridas no período de observação participante tenham orientado o estudo posterior, a pesquisa 
não se estruturou sobre esses conhecimentos, mas sim em profundo estudo da literatura e da documentação do ProJovem a respeito de objetivos, propostas e diretrizes gerais e específicas. 0 roteiro de entrevista - principal técnica utilizada - foi elaborado com base no cruzamento dos conteúdos da teoria e na análise da documentação. Na entrevista, predominou a relação proporcional entre o domínio da pesquisadora sobre a teoria e o programa e a indiscutível sabedoria dos educadores acerca da implementação cotidiana da educação inclusiva.

Martins (2004) afirma que a subjetividade do pesquisador é uma crítica comumente feita à pesquisa qualitativa. Essa mesma autora explica, porém, que a subjetividade pode ser controlada pelo domínio da teoria e da experiência técnica. Assim, o estudo da teoria permitiu superar as concepções da própria pesquisadora e a possível ameaça dos vínculos pessoais. 0 trabalho fino da análise dos dados obstou uma leitura pessoal do conteúdo das entrevistas, resultando em análise imparcial.

A defınição da quantidade de entrevistados se justifica pelo amplo volume de material reunido com o grupo, suficiente para a compreensão do objeto pesquisado. Martins (2004) debate as diferenças entre a pesquisa quantitativa e a qualitativa. A primeira, segundo ela, busca generalizar os resultados e implica preocupação com a representatividade da amostra, pois supõe que cada unidade manifesta o conjunto. $\mathrm{Na}$ pesquisa qualitativa, diferentemente, cada unidade é tomada em sua totalidade, inclusive em sua singularidade. Nesse caso, o estudo é exaustivo e intenso; mais do que os aspectos comuns apontando regras gerais, ele procura desvendar os microprocessos envolvidos na questão. As entrevistas em profundidade com os seis professores produziram material suficiente para compreensão das inúmeras variáveis que participam na construção de relações entre professor e aluno.

0 roteiro da entrevista foi estruturado a partir de cinco blocos de informação, a saber: a trajetória do educador, a caracterização do ProJovem em relação a outras experiências docentes, o perfil e a relação com o estudante, as transformações dos estudantes e os problemas vividos no programa. Os objetivos e as diretrizes do programa foram discutidos com os educadores a fim de verificar as questões envolvidas no processo e a possibilidade de tais propósitos serem alcançados.

Os resultados são a seguir apresentados segundo os blocos elaborados para o roteiro das entrevistas.

\section{Os educadores}

0 ProJovem não exige que seus educadores tenham formação e experiência docente, buscando mesclar diferentes tipos de profissionais e valorizando o conhecimento acadêmico, a experiência docente e a atuação profissional em outras áreas, sobretudo no caso da qualificação profissional e da ação social. Assim, o corpo de educadores se compunha de indivíduos com atuação na rede pública de educação e outros sem essa experiência, possibilitando uma rica troca de saberes.

Dos entrevistados, somente um dos professores não tinha experiência na rede pública. Dos cinco com experiência, apenas um tinha trajetória mais longa e regular na rede; os outros foram estagiários, substitutos ou contratados durante o ProJovem. Exceto um professor, todos os demais já tinham trabalhado com público de baixa renda, mas o programa os levou a mergulhar na realidade da vida dos educandos de modo nunca antes experimentado por eles.

A professora de qualificação profissional era técnica em publicidade e propaganda, com especialização em eventos, e ministrava aula no setor de turismo. Ela já havia trabalhado com programas na área de economia solidária e fora substituta na rede pública. 0 professor de qualificação profissional tinha formação em artes e culinária com longa experiência, inclusive como educador em escola técnica. Ele se identificou muito com o ProJovem, estimulando-se a ingressar no curso de pedagogia e a manter-se no programa mesmo após sua transferência para a Secretaria de Educação. 
A professora de ação social trabalhou com área administrativa. Estudou pedagogia e estagiou na rede pública com alunos do perfil do ProJovem. Ocupou-se em uma ONG para qualificação profissional de jovens e foi voluntária em cursinho preparatório para o vestibular. Além disso, especializou-se em educação inclusiva e, durante o ProJovem, tomou posse na rede como professora de educação infantil.

A professora de ciências humanas formou-se em história, fez ensino médio e também técnico, tinha experiência docente e tornou professora regular da rede durante o ProJovem. A professora de ciências da natureza possuía longa experiência docente. Ela fez magistério e graduação em ciências biológicas, foi professora eventual na rede por muitos anos e assumiu, na época do programa, a coordenação de uma escola pública. A professora de língua portuguesa fez magistério, graduação em letras e pedagogia, e pós-graduação em letras. Além disso, trabalhou por curto período com educação infantil em uma escola privada, sendo que o ProJovem foi sua primeira verdadeira experiência profissional. Durante o programa, ela foi aprovada e contratada pela rede municipal.

\section{As características do ProJovem}

Os educadores foram convidados a discorrer sobre aspectos positivos do ProJovem, comparando-o a outras experiências docentes. Todos eles se confessaram realizados e satisfeitos com a experiência do ProJovem.

Eles destacaram a proximidade com os alunos e com os colegas. A proximidade dos docentes com os atores do programa era satisfatória. Uma educadora comparou o relacionamento no ProJovem com o praticado na rede pública, onde, em suas palavras, "é cada um por si e Deus por todos”. Segundo ela, a união favoreceu a solução conjunta de problemas.

Mas o tema destacado foi o fato de poder ouvir o discente, trazer a realidade dele para a sala de aula e trabalhar com essa informação no processo educativo. Assim, de forma espontânea, os educadores salientaram o objeto desta pesquisa. É certo que as respostas podem refletir mais as representações dos educadores do que a realidade em si, mas tal representação orienta a ação.

Um dos educadores comentou:

A gente está construindo junto o aprendizado, sabendo o conteúdo que eles conhecem do tema e transformando junto, para que tenham um entendimento diferente. Nós adaptamos o ensino para a realidade da comunidade.

Outra educadora concluiu que, ao ouvir os alunos, ela pode ajustar as aulas às necessidades e aos limites deles próprios. Todos concordaram que conhecer a realidade do aluno possibilita preparar e apresentar melhor a aula.

Uma educadora explicou que a rede também permite relacionamento mais aberto com os alunos. A organização consolidada, porém, favorece a resistência de alguns atores. Todavia, se a flexibilidade do ProJovem possibilita relacionamentos em geral, ela também implica precariedade nas relações de trabalho e, consequentemente, insegurança, competição e animosidade.

\section{O estudante do ProJovem Urbano}

A vulnerabilidade socioeconômica e a trajetória errática de trabalhos precários foram os elementos destacados pelos entrevistados para caracterizar os discentes. Embora eles já tivessem experiência com esse público, o modelo do programa constrangeu-os à intensa proximidade com a realidade dos alunos, levando-os a participar intensamente daquelas histórias de vida. Uma das educadoras disse que os estudantes do ProJovem eram os pais de seus alunos na escola, o que a fez compreender melhor os problemas das crianças no colégio. Todos eles relataram e se mostraram solidários às tristes histórias de alunos, envolvendo precariedade, violência e morte.

Os entrevistados se referiram ao trauma com as experiências escolares pregressas dos estudantes, o que se expressava na insegurança em 
relação à capacidade de aprendizagem, exigindo investimento cuidadoso dos educadores para sua superação. 0 relato de uma educadora desvenda aspectos desse trauma, assim como as diferenças nas concepções da lógica escolar e das famílias populares. Vale ressaltar que, nesse caso, a diferença não se converteu em desigualdade. $\mathrm{Na}$ trajetória da educadora, fica manifesta sua prioridade à esfera escolar. Ela investiu nos estudos e esforçou-se para concluir a pós-graduação e tornar-se professora. Para ela, o motivo relevante que justificaria o abandono dos estudos seria a necessidade de cuidar da sobrevivência.

Os estudantes revelaram, porém, que não deixaram a escola somente pela necessidade de trabalhar, mas também por causa de namoro, gravidez, descontentamento e insatisfação, remetendo às análises de Thin (2006) de que outras esferas da vida podem ser tão ou mais importantes do que a escola. Apesar da diferença de valores, a entrevistada estava convencida de que seus alunos se sentiam fracassados com o abandono. Desse modo, a responsabilidade pelo desajuste entre o mundo da escola e o da vida era assumida pelos próprios estudantes, num movimento de legitimação da lógica escolar. Desvela-se aí o processo de reprodução da desigualdade discutido por Bourdieu (1979), pois o que difere do modelo tido como legítimo se converte em algo negativo. Independentemente das diferenças, a educadora se empenhou junto com eles na superação do trauma.

Os educadores admitiram que no início do programa tiveram problemas na utilização de técnicas que não abordavam somente habilidades cognitivas, mas também aspectos relacionais e afetivos. Os alunos se sentiram ludibriados por educadores descompromissados. 0 ludíbrio era avaliado como prejuízo, pois o tempo perdido poderia ter sido empregado com os afazeres familiares. Os educadores administraram a resistência às atividades em grupo e extrassala, ao uso de vídeos, músicas etc. Essa informação escancara uma ambiguidade por eles enfrentada. Os estudantes se sentiam traumatizados pela experiência negativa com a escola, cuja lógica convertia seus valores e suas formas de vida em algo negativo. No entanto, ao ingressarem num modelo que acolhe e valoriza a diferença e articula a lógica da escola com a realidade dos estudantes, estes resistem e reclamam a aplicação do modelo por eles abandonado. Os educadores tiveram que criar metodologias, ultrapassar os próprios limites, a insegurança e a decepção para fazer os alunos compreenderem que o processo de aprendizagem era compatível com a aplicação de elementos da realidade de suas vidas e que não dependia apenas dos aspectos cognitivos, que tanto os assustavam, mas inclusive de habilidades que eles valorizavam, como a relacional. Esse fato elucida a complexidade da implementação de um programa de educação inclusiva.

Por fim, merece destaque o fato de que, embora fosse um programa para juventude, os estudantes se percebiam adultos, com responsabilidades. Muitos eram casados e tinham filhos. Alguns pais confessaram frequentar o ProJovem para acompanhar o estudo dos filhos. Esse argumento aponta o entrecruzamento das políticas, já que a massificação do ensino básico pode estimular o retorno de alguns pais à escola.

\section{O programa e a transformação dos estudantes}

As diretrizes do programa podem provocar transformações na vida dos estudantes, afinal elas buscam estimular a reflexão crítica, a ressignificação da realidade, das práticas, das relações e da própria vida. Em relação à área de ação social, cinco educadores não observaram mudanças nos alunos, que não demonstraram desenvolvimento na conscientização cidadã, no compromisso com a comunidade e com a ação solidária.

Os professores de qualificação profıssional contaram a trajetória dos alunos, a maioria destes com experiência no mercado informal de trabalho, desempenhando atividades muito simples, inclusive domésticas. Tais estudantes não prestigiavam suas atividades e experiências, assim como não reconheciam os conhecimentos aplica- 
dos em sua execução como um saber. Para eles, tratava-se de uma não atividade, de uma experiência invisível. Com as aulas de qualificação profissional, eles aprenderam a diferença entre trabalho e emprego e passaram a valorizar suas atividades e o saber nelas implicado. Eles se reconheceram donos de um saber, portanto, com competências a serem apresentadas no mercado de trabalho. Os estudantes se conscientizaram dos direitos do trabalho, começando a avaliar criticamente as experiências no ambiente profissional. Essas aulas ainda estimularam o desenvolvimento da capacidade de planejamento dos alunos, avaliando as ações presentes e considerando a perspectiva de futuro. Eles aprenderam sobre a aposentadoria, a contribuição previdenciária e a pensar em alternativas de garantia para o futuro.

Embora sem determinar a quantidade, os educadores relataram que vários alunos conseguiram empregar-se depois do ProJovem, principalmente na área de alimentação, um dos setores de qualificação profissional do município. Um dos educadores entrevistados, devido aos seus conhecimentos na área, certamente contribuiu para criar oportunidades para seus alunos. Houve casos de jovens que transitavam no tráfico de drogas e que mudaram a vida, empregando-se no setor de alimentação e tornando-se orgulhosos de suas conquistas profissionais. Os entrevistados avaliaram os empregos em docerias, padarias e comércio em geral como um progresso em relação às ocupações anteriores. Segundo eles, vários alunos continuaram qualificando-se em cursos profissionais. Em relação à reinserção no mundo da escola, os educadores registraram que alguns deram continuidade aos estudos e muitos ingressaram no ensino médio, caminhando para a conclusão.

A elevação da autoestima, segundo uma educadora, era uma estratégia da qual eles não podiam abrir mão para que o processo de aprendizagem fosse desenvolvido. Os educadores apresentaram muitos relatos de estudantes que ingressaram com baixa autoestima e, com o tempo, melhoraram e passaram a confiar em si próprios. Uma das educadoras explicou que o progresso na aprendizagem colaborava para a elevação da autoestima. Para tanto, os professores tinham que convencer os estudantes de sua capacidade de aprender, de superar limites. Essa era uma tarefa que exigia paciência. Cotidianamente, o educador esclarecia que os alunos não tinham obrigação de saber o que era ensinado, que os próprios educadores não conheciam tudo e tinham muito a aprender com os alunos. Além disso, os professores explicavam um mesmo tema inúmeras vezes, de formas diferentes, sempre buscando relacioná-lo a aspectos trazidos pelos próprios alunos. Esse era um processo longo, mas, com o tempo, a resistência era vencida e os estudantes passavam a compreender o conteúdo com menos dificuldade. 0 tempo para desenvolver a autoestima e vencer as resistências era um drama para os educadores, porque o período empreendido com tal metodologia se chocava com o do calendário da direção nacional. Nem sempre era possível abordar todo o conteúdo, já que o tempo de aprendizagem dos alunos era mais lento do que supuseram os formuladores do programa.

Havia um caso paradigmático de recuperação de autoestima, citado orgulhosamente por vários educadores: o de um aluno de inclusão com problemas de saúde, entre eles, epilepsia. Segundo os entrevistados, o menino frequentara por anos a escola regular, sem nenhuma transformação. Matriculado no ProJovem, ele ingressou tímido, isolado dos colegas. Os professores o acolheram com respeito e, aos poucos, conquistaram-no. Ao se sentir acolhido, o jovem foi se desarmando e se aproximando dos educadores e dos colegas. Por fim, ele progrediu na habilidade relacional, conseguindo até mesmo empregar-se num supermercado, em vaga para inclusão. Vale ressaltar que o sucesso apontado concentrou-se nas capacidades relacionais e afetivas, e não na cognitiva. Mas os educadores não se sentiam menos orgulhosos por isso, afinal, julgavam que o aluno reinterpretou suas relações com o mundo, tornando-se, segundo eles, uma pessoa mais feliz. 
Um ponto que merece registro é o trabalho dos educadores para lidar com a dificuldade de domínio cognitivo de certos temas por parte dos estudantes. Paixão (2005) aborda essa questão ao explicar, a partir dos resultados de sua pesquisa, a ênfase das classes populares nas dimensões afetiva e racional, em detrimento da cognitiva, ao analisarem as interações com a escola. A educadora de ação social descreveu sua sofisticada estratégia para tentar superar essa dificuldade. Ela relatou um debate sobre a violência contra a mulher, no qual uma parte dos alunos argumentou que "apanha quem quer”, e a outra nem quis discutir. Um tema comum ao grupo, como esse, era mais difícil de ser trabalhado, porque parte das alunas era vítima e parte dos alunos era agressor. A educadora relatou que, em tais debates, eram comuns as posições opostas e estanques, a recusa da discussão, o apelo emocional e o desrespeito à divergência.

Para convencer os alunos a ultrapassarem as respostas imediatas e emocionais, a considerarem aspectos mais amplos envolvidos na questão, ela introduzia um vasto volume de informações, relacionando-as com elementos estruturais. Para tanto, era preciso apresentar notícias, dados, histórias, reportagens, entrevistas e depoimentos de especialistas a fim de que os alunos conferissem que o tema não se restringia a um aspecto, mas era uma parte da realidade mais ampla. Após a longa caminhada, os estudantes se convenciam de que o tema não se limitava ao que eles conheciam e viviam no próprio bairro, entre conhecidos, mas também englobava elementos complexos relacionados a uma configuração histórica de poder e dominação. Depois de inúmeros debates, os estudantes passavam a analisar as questões não apenas com base na experiência imediata, mas posicionando-se de modo impessoal, avaliando os diversos aspectos envolvidos e suas conexões com um universo amplo. Sem dúvida, vivenciar essa transformação dos alunos deve provocar satisfação, mas, para alcançar esse ponto, era necessário elevado investimento em pesquisa, reflexão e desenvolvimento de tecnologias didáticas.

As mudanças verificadas na dificuldade em lidar com a dimensão cognitiva levantam outro problema dos alunos, a saber: aceitar a alteridade. Até porque esta última envolve argumentos racionais ancorados em princípios abstratos de igualdade e direitos comuns. Habituados a organizarem as relações com o mundo a partir do espaço imediato, das relações próximas, os conflitos eram interpretados segundo verdades conhecidas, pautadas pela emoção e associadas a fatos estereotipados. 0 trabalho paciente e generoso desses educadores expandiu os limites de pensamento dos estudantes, preparando-os para atitudes mais tolerantes.

Esse processo de transformação se relaciona ao argumento de Barboza, Santos e Araújo (2011) de que o ponto de partida é a realidade do aluno, mas o objetivo é, com ela, caminhar além, possibilitando que o estudante aproprie-se criticamente de novas linguagens e conhecimentos. Ou seja, deve-se respeitar a realidade do aluno, mas é necessário dar oportunidades para que ele a amplie, para que possa refletir autonomamente e construir sua própria posição.

A análise de uma educadora parece acertada para descrever o processo de transformação de alguns alunos do ProJovem:

Depois de tudo, conseguiam avançar, porque às vezes iam vivendo assim, por viver, um dia após o outro, sem pensar, sem planejar. [...] se a pessoa não sabe quem ela é, quem foi seu pai, como saber o que pode oferecer para a comunidade?

A experiência desses educadores no ProJovem ensina que o respeito e a valorização das diferenças favorece a construção de uma relação mais aberta com os educandos, o que proporciona certa satisfação e realização para ambas as partes. E isso sem renegar nem anular os valores e a cultura de cada um, mas ampliando seus conhecimentos e suas perspectivas de 
mundo. 0 conflito entre as diferentes lógicas esclarecidas por Thin (2010) pode ser positivo, já que ambas as partes desenvolvem-se com o intercâmbio.

Entretanto, uma educadora refletiu lucidamente sobre os limites na transformação dos estudantes do ProJovem, chamando atenção para fato relevante. Segundo ela, muitos desenvolveram ações sociais interessantes, leram livros e visitaram locais antes desconhecidos, como museus. Todavia, talvez poucos tenham prosseguido nesse caminho após a conclusão do programa. Isso porque nem todos tinham condições culturais ou financeiras para usufruírem sozinhos desses bens. 0 programa é incapaz de solucionar os vários problemas da realidade social desses alunos.

As relações respeitosas descritas pelos professores provocaram transformações em alguns estudantes, elevando a autoestima, estimulando a reinserção escolar, profissional etc. Porém, não é possível afirmar que todos os estudantes que responderam de forma positiva a esse padrão de relacionamento entre professor e aluno permitiram-se transformações e, muito menos, alcançaram bom aproveitamento escolar. Esta pesquisa limitou-se a estudar a construção da relação entre professor e aluno, e não o aproveitamento dos beneficiários do ProJovem.

Leão e Nonato (2011) investigaram sobre alunos do ProJovem e concluíram que as relações por eles construídas com o programa dependem dos significados e das motivações com o processo de escolarização. Logo, as respostas dos alunos às ações dos educadores são variadas.

As informações sobre a evasão fazem com que se questione o entusiasmo com o programa. Tais informações eram alarmantes no período da observação participante e das entrevistas. No início, mais de 1.600 jovens se inscreveram, mas apenas cerca de 500 fizeram o exame do segundo ciclo, ou seja, menos de um terço deve ter concluído o curso. Dessa forma, não se busca relacionar a possibilidade de estabelecimento do relacionamento entre professor e aluno baseado no respeito e na valorização das diferenças como fórmula para garantir bom aproveitamento escolar. É certo que uma relação marcada pelo conflito, que transforma diferença em desigualdade, certamente não seria mais eficiente. A ocorrência de êxito ou fracasso em relação ao aproveitamento exige estudos aprofundados, considerando as inúmeras variáveis que envolvem os resultados alcançados.

\section{Problemas}

Em virtude das diretrizes do ProJovem, que exigem aproximação com o estudante e sua realidade, o professor é um elemento essencial. Ressalta-se a relevância do material didático, inclusive para o encaminhamento da ação dos educadores. Porém, as propostas do programa não podem ser concretizadas sem o engajamento desses profissionais.

Apesar da centralidade do papel do educador, o vínculo de trabalho é precário. A educadora contou que o contrato era registrado para um ano ou um ano e meio, podendo haver demissão antes do prazo ou extensão do tempo. Em 2010, o rendimento do educador correspondia a aproximadamente quatro salários mínimos. A educadora explicou que só permanecia no programa quem não dependia exclusivamente dele para sobreviver, contando com outras fontes de renda. 0 motivo da permanência era a gratificação com seu modelo. Muitos educadores denominavam a experiência no ProJovem como estágio, em virtude da instabilidade do programa em relação ao futuro.

Nas palavras da entrevistada, o período que antecedia o fim do contrato era "angustiante”, porque não havia certeza de recontratação. Todos torciam para que houvesse matrículas suficientes, garantindo a permanência no programa. Segundo ela, após a conclusão das matrículas, o "desespero" era relativo à evasão, que obrigava o enxugamento dos núcleos e a consequente demissão de educadores. Outros educadores esclareceram que a não explicitação dos critérios para as demissões também gerava insegurança, porque o educador não 
tinha controle sobre o que seria analisado no seu desempenho. As demissões também impactavam os estudantes, que em alguns casos se revoltavam e resistiam ao substituto.

A frágil relação das escolas com o programa foi outro problema levantado. Atualmente, o ProJovem está sob a responsabilidade da Secretaria Municipal de Educação, mas na época, não. A direção das escolas não demonstrava comprometimento com o programa e, como concluiu uma entrevistada, quando a direção não é a favor, dificilmente os outros membros agirão de forma diferente. Sem apoio da escola, os educadores não tinham espaço para desenvolver as atividades de planejamento e atendimento dos alunos nas duas horas que antecediam o início das aulas. 0 acesso a material e computadores também podia ser dificultado. Havia, ainda, reclamação de que as atividades do programa causavam transtornos, incomodando as aulas de educação de jovens e adultos (EJA).

Talvez um dos principais problemas provocados pela direção fosse a perseguição a alunos que haviam sido expulsos da escola. A direção e os funcionários tratavam alguns desses alunos com desconfiança, reproduzindo o mesmo padrão de comportamento que provocou o conflito e a expulsão do estudante. Dessa forma, o investimento dos educadores do ProJovem para superar o trauma com a trajetória escolar era ameaçado constantemente.

A formação continuada foi a principal reclamação dos educadores. Barboza, Santos e Araújo (2011) argumentam que a formação inicial e continuada - é fundamental para que os educadores complementem sua formação para além dos conhecimentos específicos de suas áreas e também se apropriem dos significados da proposta pedagógica. É possível considerar que, num programa inovador e dependente da centralidade do educador, a formação é elemento-chave. Todavia, a formação continuada foi muito frágil. Os educadores contratados na primeira versão frequentaram a formação no Rio de Janeiro e elogiaram a oportunidade, porque foram informados dos objetivos do programa, compreendendo o que e como deveriam fazer. Mas os contratados ao longo do processo não foram introduzidos nem mesmo ao projeto pedagógico integrado, desconhecendo os objetivos do ProJovem. No início de cada unidade formativa, eles deveriam receber formação sobre o tema, sobre as possibilidades de abordagem interdisciplinar e sobre as maneiras para pesquisarem e obterem dados a serem trabalhados na sala de aula. Eles ainda deveriam ter liberdade para debater os problemas enfrentados no desempenho das atividades, trocando experiências com os colegas e buscando soluções coletivas com estes e com os formadores. Porém, a formação continuada perseguiu o modelo tradicional de relacionamento entre professor e aluno - questionado pelo próprio ProJovem -, porque os formadores não ouviam os educadores e muitas vezes transmitiam informações que não podiam ser aplicadas na sala de aula, por não conhecerem os alunos do programa, o ambiente de trabalho dos educadores e a realidade do município onde o programa estava sendo implementado. A consequência é que os educadores trabalhavam sozinhos. Essa dedicação solitária pode ser constatada na descrição da preparação para o debate sobre violência contra a mulher: a educadora fez toda a pesquisa e elaborou a tecnologia dos recursos didáticos sozinha.

Sem o apoio imprescindivel da formação continuada, os possíveis êxitos do programa podem ser atribuídos, sobretudo, à dedicação dos educadores. 0 problema é que, desse modo, o sucesso dos educadores pode ser relacionado a dons pessoais; em contraste, o insucesso de outros pode ser explicado pela falta de talento ou de aplicação individual. Um exemplo disso é a relevância atribuída pelos educadores aos conhecimentos adquiridos nos cursos de magistério e pedagogia. Um dos objetivos do ProJovem era reunir educadores com trajetórias ocupacionais diferentes, a fim de integrar a diversidade de saberes. Mas, para tanto, seria importante que os contratados sem experiência didática fossem apoiados pela formação. Sem 
isso, o domínio da formação didática era uma vantagem que excluía quem não a possuía.

\section{Conclusões}

0 estudo buscou verificar a implementação de diretrizes do ProJovem, investigando se esse processo contribuiria para o estabelecimento de relações entre professor e aluno baseadas no respeito e na valorização das diferenças, de forma que os valores e a cultura dos alunos não fossem deslegitimados diante dos da lógica escolar.

Em primeiro lugar, a análise das entrevistas permite considerar que as diretrizes apontadas no plano pedagógico são concretizadas. Algumas dessas diretrizes são: valorizar os conhecimentos prévios dos estudantes, os quais devem ser tomados como ponto de partida para a aprendizagem; reconhecer e valorizar as diferenças; orientar as atividades de acordo com a potencialidade e o ritmo do aluno; propiciar oportunidade de escolha na solução de problemas; adaptar os conteúdos à realidade local; registrar a trajetória familiar e estimular o trabalho coletivo. Quando o educador desenvolve tais diretrizes, ele conquista a confiança do estudante, o qual passa a se identificar com a proposta do programa. Desse modo, alguns dos objetivos gerais são alcançados, como o oferecimento de novas formas de interação e novos conhecimentos, a reelaboração de experiência e visão de mundo, a afirmação da dignidade como ser humano. 0 conteúdo das entrevistas sugere dúvidas em relação à afırmação da dignidade como trabalhador e cidadão, assim como em relação à transformação dos estudantes em leitores, planejadores sensíveis à estética e usuários de tecnologia. A implementação das estratégias não necessariamente conduz ao êxito na finalidade básica do programa, a saber: formação integral associando educação básica, qualificação profissional e ação social.
As diretrizes são implementadas somente junto ao grupo de alunos interessados e que permanecem longo tempo no programa. A maior parte deles desiste antes da conclusão. Entretanto, esse fato não invalida as lições que a experiência desses educadores ensina sobre o estabelecimento de relações mais abertas com os alunos, inclusive sobre problemas que devem ser evitados.

A atuação dos entrevistados no ProJovem esclarece que é possível construir relações entre professor e alunos de classes populares sem a marca da desigualdade, da dominação. As entrevistas descrevem um pouco como se dão as relações entre alunos de classes populares e a escola, tema investigado por Thin (2010). Observase que essa relação pode ser respeitosa apesar das diferenças. Thin (2006) e Paixão (2005) demonstram que, na lógica da socialização das famílias populares, o raciocínio lógico e abstrato não predomina sobre os elementos afetivos e relacionais. As experiências dos entrevistados no ProJovem apontam a articulação entre as duas lógicas com consequências positivas para ambos os lados. Nota-se também que atualmente a lógica escolar é mais flexível e considera todos os elementos do processo educativo. Além disso, a politica assimilacionista é contestada e as políticas de educação visam romper com essa tradição, sendo o ProJovem parte desse projeto.

As propostas do programa podem colaborar para a transformação de um modelo que promove a exclusão do aluno. Porém, no contexto da pesquisa, os educadores foram os grandes responsáveis por esse movimento. Numa relação de trabalho avaliada como estágio o compromisso do educador pode ser maior com o educando do que com a gestão do programa, possibilitando problemas sérios em sua implementação. 0 que 0 material das entrevistas sugere é que se houvesse maior investimento na formação continuada e maior apoio nas atividades dos educadores, o êxito na implementação das diretrizes poderia ter sido ainda maior. 


\section{Referências}

ANDRADE, Eliane da; ESTEVES, Luiz, C. G.; OLIVEIRA, Edna C. de. Composição social e percursos escolares dos sujeitos do ProJovem: novos/velhos desafios para o campo da educação de jovens e adultos. Em Aberto, Brasília, v. 2, n. 2, p. 73-89, nov. 2009.

BARBOZA, Jamille de; SANTOS, Cleber S. dos; ARAÚJO, Manuela B. de. Interdisciplinaridade no ProJovem Urbano: uma prática em construção. In: COLÓQUIO INTERNACIONAL “EDUCAÇÃO E CONTEMPORANEIDADE”, 5., 2011, São Cristóvão. Anais... São Cristóvão, 2011.

BOURDIEU, Pierre. La distinction critique social du jugement. Paris: Minuit, 1979.

BRASIL. Secretaria Nacional de Juventude. Projeto Pedagógico Integrado do ProJovem Urbano. Brasília: Programa Nacional de Inclusão de Jovens (Projovem Urbano), 2008.

Projovem Urbano. Exame nacional externo: $2^{\circ}$ ciclo, Brasília, 2009.

CANDAU, Ana. Universos culturais e representações docentes: subsídios para a formação de professores para a diversidade cultural. Educação e Sociedade, Campinas, v. 21, n. 77, p. 207-227, dez. 2001.

CANEN, Ana. Universos culturais e representações docentes: subsídios para formação de professores para a diversidade cultural. Educação e Sociedade, Campinas, v. 22, n. 77, p. 207-227, 2001.

COSTA, Márcio da. Projovem: notas sobre uma política nacional para jovens de baixa escolaridade. Revista Contemporânea, Rio de Janeiro, v. 3, n. 3, p. 1-6, 2007.

FÉRES, Maria José V. et al. Textos complementares para formação de gestores. Brasília: ProJovem Urbano, 2008.

LEÃO, Geraldo P. L. M. Experiências da desigualdade: os sentidos da escolarização elaborada por jovens pobres. Educação e Pesquisa, São Paulo, v. 32, n. 1, p. 31-48, jan./abr. 2006.

LEÃO, Geraldo P. L. M.; DAYRELL, Juarez Tarcísio; REIS, Juliana Batista dos. Jovens olhares sobre a escola do ensino médio. Cadernos CEDES, Campinas, v. 31, n. 84, p. 253-273, mai.-ago. 2011.

LEÃO, Geraldo, P. L. M.; NONATO, Symaira P. Trajetórias de estudantes do ProJovem Urbano em Belo Horizonte. In: CONGRESSO INTERNACIONAL DA ASSOCIAÇÃO LATINO-AMERICANA DE SOCIOLOGIA, 28., 2011, Recife. Anais... Recife: UFPE, 2011.

MARTINS, Heloísa Helena. Metodologia qualitativa de pesquisa. Educação e Pesquisa, São Paulo, v. 30, n. 2, p. 289-200, 2004. MENDES, José Manuel; SEIXAS, Ana Maria. Escola, desigualdade e a questão educativa em Pierre Bourdieu. Educação, Sociedade e Culturas, Porto, n. 19, p. 103-129, 2003.

PAIXÃO, Lea P. Significado da escolarização para um grupo de catadoras de um lixão. Cadernos de pesquisa, São Paulo, v. 35, n. 124, jan./abr. 2005.

SANTOS, Roni Peterson. Como ocorre a relação com o saber no ProJovem Urbano? In: COLÓQUIO INTERNACIONAL "EDUCAÇÃO E CONTEMPORANEIDADE", 5., 2011, São Cristóvão. Anais... São Cristóvão, 2011.

THIN, Daniel. Para uma análise das relações entre famílias populares e escola: confrontação entre lógicas socializadoras. Revista Brasileira de Educação, São Paulo, v. 11, n. 32, p. 211-370, maio/ago. 2006.

Famílias populares e instituição escolar: entre a autonomia e heteronomia. Educação e Pesquisa, São Paulo, v. 36, n. especial, p. 65-77, 2010.

Recebido em: 04.07.2012

Aprovado em: 18.09.2012

Maria Inês Caetano Ferreira é mestre e doutora em Sociologia pelo Departamento de Sociologia da Universidade de São Paulo. Atualmente é professora adjunta da Universidade Federal do Recôncavo da Bahia. 